\title{
El valor narrativo de la comunicación en la danza contemporánea: habitus, musicalidad y emoción
}

\author{
Dafne Muntanyola ${ }^{1}$; Simone Belli²
}

Recibido: 8 de octubre 2015 / Aceptado: 22 de febrero 2016

Resumen. La riqueza de la danza viene de la necesidad de trabajar con cuerpos. Pero el cuerpo del bailarín pertenece a un contexto plural, cruzado por tradiciones artísticas y sociales que posiciona el artista en un campo determinado. Partimos de la premisa de que el conflicto de roles es un componente esencial de la estructura de la creación artística colectiva. Analizamos los discursos de los miembros de una compañía de danza inglesa, parte del proyecto etnográfico 'Dance and Cognition', dirigido por David Kirsh de la Universidad de California, junto con la WayneMcGregor-Random Dance Company. Aplicamos un Análisis Crítico del Discurso a un corpus de entrevistas enfocadas en las emociones, la música y la danza. Demostramos cómo la creatividad en danza se puede observar empíricamente, como un producto social distribuido y corpóreo, articulado por el habitus de la danza.

Palabras clave: narrativa; danza; habitus; emoción; música; memoria.

\section{[en] The Narrative Value of Dance Communication: habitus, musicality and emotion}

\begin{abstract}
The richness of dance comes from the need to work with an individual body. Still, the body of the dancer belongs to plural context, crossed by artistic and social traditions, which locate the artists in a given field. We claim that role conflict is an essential component of the structure of collective artistic creativity. We address the production of discourse in a British dance company, with data that spawns from the ethnography 'Dance and Cognition', directed by David Kirsh at the University of California, together with WayneMcGregor-Random Dance. Our Critical Discourse Analysis is based on multiple interviews to the dancers and choreographer. Our findings show how creativity in dance seems to be empirically observable, and thus embodied and distributed shaped by the dance habitus of the particular social context.
\end{abstract}

Keywords: narrative; dance; habitus; emotion; music; memory.

Sumario. 1. Introducción. 2. Metodología. 3. Resultados. 3.1. El habitus musical de ballet clásico, la danza moderna y la contemporánea. 3.2. La memoria de las bailarinas: la música cómo herramienta. 3.3. El valor narrativo de la comunicación en danza. 4. Conclusiones. 5. Referencias bibliográficas.

Cómo citar: Muntanyola, D., Belli, S. (2016) El valor narrativo de la comunicación en la danza contemporánea: habitus, musicalidad y emoción. Revista de Antropología Social 25(1), 133-151.

\footnotetext{
1 Universidad Autónoma de Barcelona

dafne.muntanyola@uab.cat

2 Yachay Tech

sbelli@yachaytech.edu.ec
} 


\section{Introducción}

"How can we know the dancer from the dance?" William Butler Yeats (1928)

Abordamos en este articulo la relación entre música y danza a partir de una etnografía de una compañía de danza inglesa, realizada entre 2009 y 2012 en Londres (Kirsh et al, 2009). Nos basamos en 12 entrevistas semi-estructuradas, notas de campo y material audiovisual. Nuestro análisis se centra en el rol que ejerce la música en los miembros de la compañía para descubrir su valor narrativo. Se trata de trazar una historia que representa la conjunción y la conexión entre la danza, la música y la coreografía.

En primer lugar, traducimos aquí empíricamente el concepto del antropólogo y sociólogo Pierre Bourdieu (1991) de principio de habitus. En palabras de Bourdieu, se trata de un sistema de esquemas interiorizados que permitirían engendrar todos los pensamientos, percepciones y acciones características de una cultura (Bourdieu, 1967). De este modo, la música y la danza puede analizarse como la resultante de la relación entre las estructuras objetivas externas y las estructuras internalizadas e incorporadas, al remitir a la posición que ocupan los bailarines en la coreografía.

Más allá de los esquemas dualistas del habitus (música y danza), definiremos también el rol de la música como elemento clave de la competencia, habilidad o skill tanto de las bailarinas como de los coreógrafos. Mediante los conceptos de cognición corpórea (embodied cognition) exploramos la existencia de una habilidad de las bailarinas. Existe literatura abundante en antropología cognitiva y en filosofía sobre el concepto de body memory (memoria corpórea), sobre la cual los bailarines trabajan para crear y aprender nuevos pasos (Merleau-Ponty, 1962; Dreyfus \& Dreyfus, 1986; Dreyfus, 1996; Gallagher, 2005; Gallagher \& Ramsøy, 2006; Noë, 2005; Todes, 2001). En términos fenomenológicos, esta capacidad cognitiva es el producto de la intencionalidad motora de los miembros de la compañía y de sus estrategias imaginativas, en un flujo espacio-temporal. El acto de escucha y memoria musical sería un proceso creativo, siguiendo también al interaccionista Goffman $(1969,1983)$, que tiene que darse necesariamente en un espacio físico definido socialmente. El etnometodólogo Garfinkel (1967) extiende la dimensión artística de la producción y percepción musical en danza al hecho de que todos los sujetos sociales son conscientes de su experiencia compartida (Garfinkel, 2006: 116). Esta dimensión intersubjetiva de la comunicación creativa es definida por el antropólogo Roy D'Andrade (1995) como el conocimiento que emerge cuando "todo el mundo sabe que todo el mundo sabe que todo el mundo sabe". Desde estas perspectivas, la memoria de un movimiento pasa a ser parte de este gran conjunto de capacidades cognitivas que llamamos conocimiento distribuido y corpóreo (Giere \& Moffat, 2003; Rogers, 2006). La etnografía que constituyó el trabajo de campo para este artículo se inscribe en esta perspectiva teórica, complementando otros trabajos etnográficos en entornos profesionales diversos como el teatro (Noice y Noice, 1997), los hospitales (Lozares, 2007), la arquitectura (Murphy, 2004), los mundos del arte (Becker, 1982; Becker, Faulkner y Kirshenblatt-Gimblett, 2006) o los laboratorios científicos (Knorr-Cetina, 1999). En música, Pelinski (2005) ofrece una exhaustiva revisión de etnografías musicales, que complementamos con Muntanyola y Belli (2014) y el presente artículo. 
En definitiva, mediante la reconstrucción del habitus de danza neoclásico y de la visibilización de estrategias cognitivas propias, buscamos responder a la siguiente pregunta de investigación: ¿La memoria musical de las bailarinas es una habilidad cognitiva producto del habitus dominante del campo de la danza, o bien una estrategia de resistencia creativa, corpórea y discursiva? Para llegar a la definición social de la escucha musical como producto emergente, identificaremos por lo tanto los posibles conflictos comunicativos y funcionales entre los miembros de la compañía. Esta dimensión distribuida del conocimiento, puede precisamente estar a la base del habitus de la compañía de danza observada.

\section{Metodología}

En este artículo ofrecemos un análisis basado en los datos discursivos que provienen de la investigación interdisciplinaria Dance \& Cognition, dirigida por el profesor David Kirsh, del departamento de ciencia cognitiva de la University of California, San Diego (UCSD). Se trata de una etnografía cognitiva de un proceso creativo (Muntanyola. D., 2010), realizada conjuntamente con la compañía londinense Wayne McGregor | Random Dance. Siete cámaras de alta resolución, acompañado de notas de campo tomadas por los investigadores y estudiantes de la UCSD, han capturado un proceso completo de ensayo y producción de tres piezas: DYAD en enero y setiembre de 2009; FAR, de agosto a noviembre de 2010; y UNDANCE, de agosto a octubre de 2011.

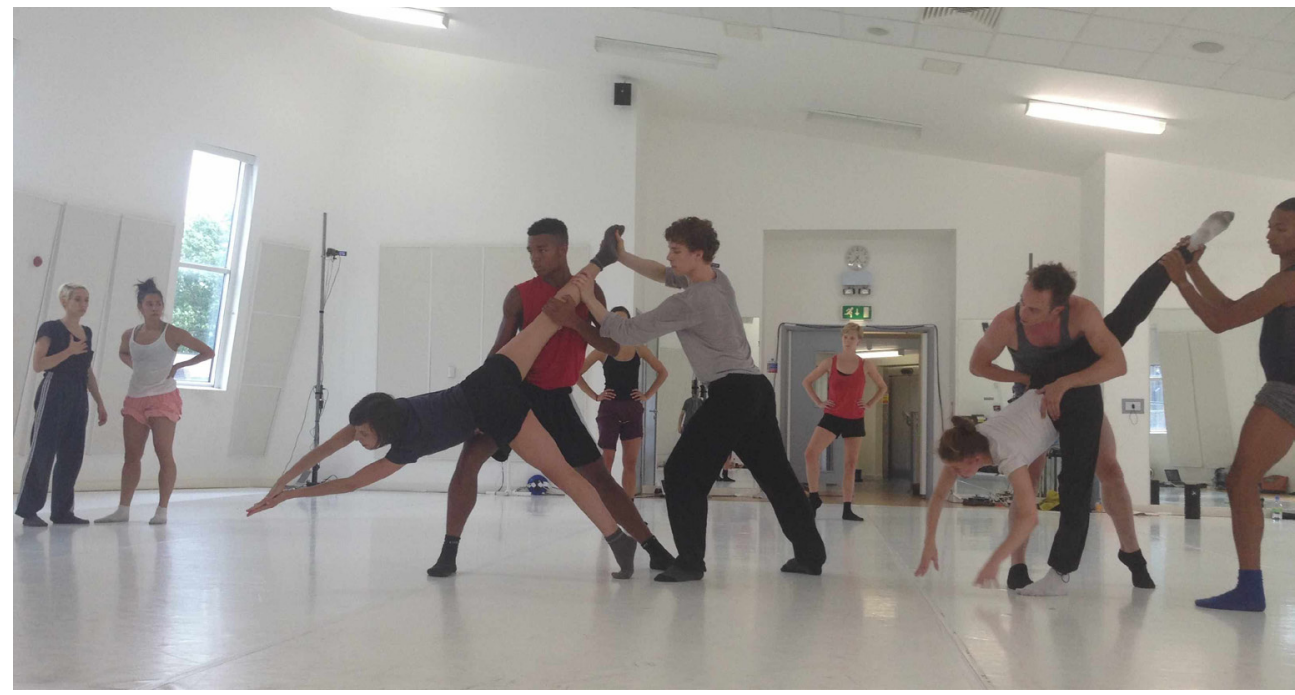

Figura 1. Ensayos de la compañía Wayne McGregor | Random Dance.

Durante las semanas de ensayos, tanto en San Diego como en Londres, se entrevistaron y filmaron diariamente a los bailarines y al coreógrafo. Gracias a la extensiva recogida de datos audiovisual, y el posterior análisis cualitativo del video, se 
mesuraron y explicaron diversos fenómenos cognitivos que captaron nuestra atención. Contrastamos y complementamos el discurso de los participantes con lo que podíamos captar de su comportamiento durante los ensayos. La anotación temporal resultó crucial para reconstruir la narrativa de lo sucedido y facilitar así la comparación de notas entre observadores de un mismo acontecimiento, corrigiendo eventuales errores en la recogida de datos. Para indexar el material audiovisual utilizamos el programa de análisis cualitativo ELAN®, desarrollado por el Max Planck Institute for Psycholinguistics (ver Figura 2). Clasificamos el proceso de trabajo coreográfico en episodios de actividad recurrente (Activity Recurrent Episodes), definidos como actividades reiteradas, relevantes, y delimitadas por un cambio en el contenido de la interacción (Barab, Hay y Yamagata-Lynch, 2001: 66).

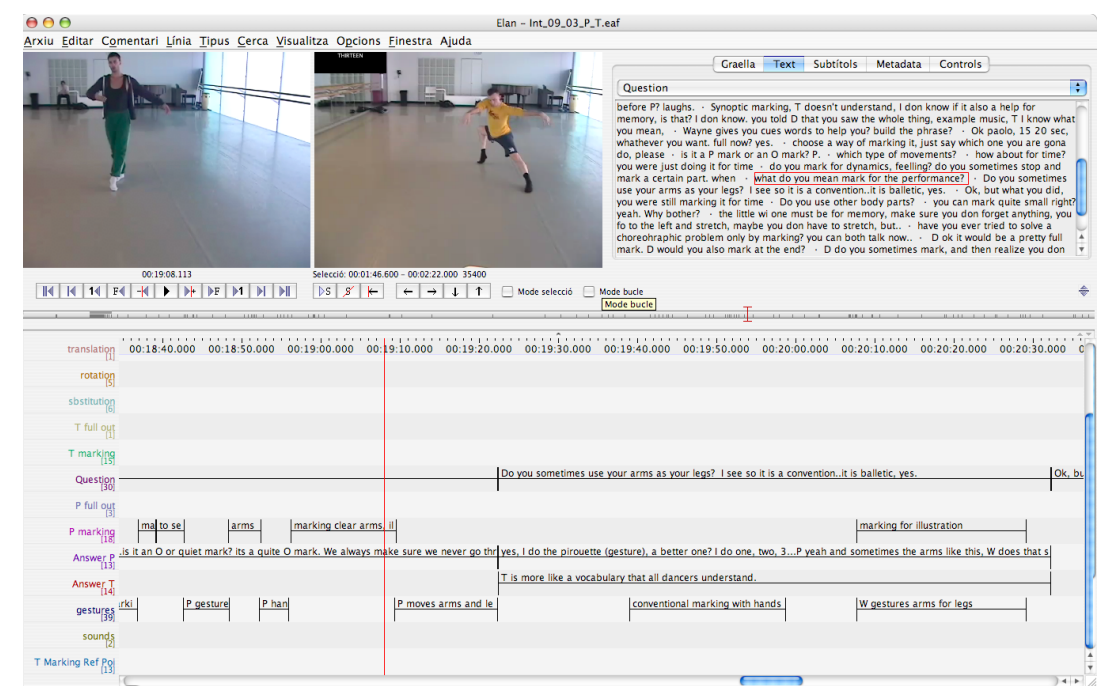

Figura 2. Imagen de un momento de análisis del video de las entrevistas con ELAN.

Para el presente artículo hemos analizado dos tipos de material discursivo. Cuatro de las entrevistas recogidas en este artículo se realizaron a las bailarinas que ensayaban por el montaje UNDANCE, que se estrenó en 2011 en Sadler's Wells, Londres. Las entrevistas, de una duración media de 30 minutos, se realizaron en inglés (segunda lengua de las entrevistadas) a bailarinas de la compañía de origen diverso (Portugal, Polonia, Suiza y España), en julio de $2011^{3}$. Las otras tres entrevistas al coreógrafo Wayne McGregor y a cuatro coreógrafos más, dos de género masculino y dos de género femenino, del departamento de danza de la University of California, San Diego (UCSD). Las entrevistas duraron entre 60 y 90 minutos y tuvieron lugar entre enero de 2009 y enero de 2010. Todas las entrevistas se grabaron en video y fueron realizadas por la entrevistadora, que forma parte del proyecto Dance \& Cognition y es co-autora de este artículo. Se siguió un guión semi-estructurado, dinámi3 Por razones de confiablidad hemos anonimizado los nombres de las entrevistadas, pero no el del coreógrafo, ya
que da el nombre a la misma compañía. 
co y flexible. Las entrevistas fueron transcritas por los autores de este artículo y por estudiantes de la University of California, San Diego.

El procedimiento de análisis se articula en tres pasos bien distintos. En la primera etapa se analizan las representaciones discursivas, estrategias argumentativas (por ejemplo, la polarización entre "Nosotros"/“Ellos"), los recursos lingüísticos y sus formas de auto-designación. Una vez justificados los sujetos que cumplen la acción, podemos distinguir, en una segunda etapa, y gracias a los resultados obtenidos de la etapa anterior, cómo éstos se sitúan discursivamente. Podemos estudiar las estrategias discursivas y argumentativas de los sujetos, la configuración de su rol, valor e importancia social en la compañía. Y por último, gracias a la delimitación de procesos subjetivadores, cruciales en el estudio de las emociones, podemos entender cómo se manifiestan algunas dinámicas en la compañía, a través específicamente del rechazo y la identificación. Los dos procesos tienen que ver con la relación social y lingüística de los miembros del cuerpo de baile, y el rechazo (o identificación), de la imagen y de los rasgos asignados al grupo desde otros grupos (la construcción de una imagen negativa del "ellos", por ejemplo). También se podrá observar, gracias a la diferenciación lingüística, el rechazo (o identificación) de las normas y estilos de vida de los Otros.

En la siguiente sección, se analizan los fragmentos más representativos del total de extractos analizados, según el modelo que aquí presentamos. Nuestro análisis se basa en el Análisis Crítico del Discurso (Wodak \& Meyer, 2003), enriquecido por la teoría del posicionamiento (Harré, 1989) para analizar esta construcción de cuerpos y espacios en que el sujeto se posiciona. Se trata de un proceso dinámico generado por la comunicación de los hablantes, que considera la conversación como la actividad humana más importante de todas porque abarca virtualmente todo fenómeno social conocido. Y de la misma manera, abarca muchos fenómenos mentales, como actitudes y emociones, presentes en la producción discursiva. El posicionamiento define cómo los interactuantes están posicionados y monitorizan sus posiciones (verbalmente o no verbalmente). Estos dos aspectos acompañan la mirada crítica sobre la observación del espacio físico y de sus cambios, después de que los participantes configuren sus actividades y produzcan e interpreten movimientos implicados de manera secuencial en la interacción.

\section{Resultados}

A continuación presentamos los resultados de nuestro análisis, que sigue los objetivos incluidos en nuestra pregunta inicial. Nos plantearemos hasta qué punto la capacidad de memoria musical de las bailarinas es un producto del habitus dominante del campo de la danza, o bien si se trata de una estrategia de resistencia creativa, tanto corpórea como discursiva.

\subsection{El habitus musical de ballet clásico, la danza moderna y la contemporánea}

Para Bourdieu (1991), el habitus es un sistema de disposiciones duraderas y transferibles, objetivamente "reglado" y "regulado" sin ser el producto de la obediencia a reglas, ni de la acción organizadora de un director de orquestra, o de un coreógrafo. En todos los campos artísticos se producen habitus según esta concepción, produ- 
ciendo rivalidades entre las distintas disciplinas que lo componen. Esta dinámica es particularmente visible cuando múltiples disciplinas deben "dialogar" para definir unos criterios de valor y de calidad, como en el caso de la música y la danza. En el ballet, los criterios musicales del director de orquestra no siempre tienen que coincidir con los de la danza, ya que trabajan materiales distintos (los instrumentos versus los cuerpos de los bailarines) y siguen principios de composición y de representación basados en caminos divergentes. Existe en la danza clásica un respeto y una consideración a las composiciones musicales.

En el habitus moderno y contemporáneo, en cambio, se elimina la música del escenario de danza. La compañía observada 'baila' entre dos aguas estilísticas, la clásica y la moderna, lo que le lleva a ser denominada por la crítica como danza neoclásica. Por lo tanto, explicaremos hasta qué punto y de qué manera el habitus neoclásico en danza es un mecanismo de competencia artística, siguiendo los relatos de sus protagonistas.

\section{Extracto (ex.) $12^{4}$}

91. Entrevistadora: ¿Escuchabais música [durante los ensayos]?

92. L:No, no para aquel entonces, ahora sí. Pero ella [la coreógrafa] hubiera

93. estado de acuerdo con Merce Cunningham, lo citaba y decía: 'La música

94. es la verdadera enemiga de la danza'.

Las palabras que uno de los coreógrafos contemporáneos entrevistados atribuye a Merce Cunningham, padre de la danza moderna, representan el enfrentamiento simbólico entre música y danza. La revolución de la danza moderna en los años '50 y '60 modificó la estructura de los ensayos y, en consecuencia, cambió la localización de la música y la escenografía en este proceso de creación. La música empezó a resultar innecesaria para la coreografía y en algunos casos, molesta (ex.12, 94). Existe una disyunción clara entre danza y música, a la que se le hace asumir el rol de enemiga. A diferencia de la danza clásica o ballet, la música pasa a ser un elemento de contraposición con la coreografía mainstream de la danza contemporánea.

En el siguiente extracto, vamos a introducir con las palabras de este mismo coreógrafo un elemento que parece ser clave en la preparación de un espectáculo de danza, el timing:

\section{Extracto 13}

96. L: La orden principal era 'Ya!'. Así es cómo sabíamos el timing.

97. E: ¿Te decía '¡Alto!'?

98. L: No, decía 'Bueno, esto es el final'. Y así sabíamos cuál era el final.

99. (․) Si, tenía un sentido del timing interno.

Como en todas las disciplinas artísticas, la danza se enriquece y articula un lenguaje técnico y específico, como la palabra 'timing'. En el extracto 13, esta palabra prácticamente reemplaza el término música. Este 'timing' se corresponde a órdenes bien precisas, que se articulan entre el 'YA!' y el 'Bueno, esto es el final', que identifican cuando comienza y termina una frase. Esta acción performativa (Austin, 1962) incluye los atributos de internalidad y de orden verbal, ligada a la repetición de los

4 En los extractos, se subrayarán en negrita las palabras más significativas para nuestro análisis. 
pasos. La creatividad de las bailarinas se potencia, tal como nos cuenta el coreógrafo, cuando se mantiene una discordancia intencional entre la música de los ensayos y la banda sonora final de la representación. Esta discordancia parece jugar con la idea de la affordance musical (Menin y Schiavio, 2012). Una contraposición entre música y danza emerge, por lo tanto, en las entrevistas de los coreógrafos.

Como afirma otra de las coreógrafas entrevistadas, el método de instrucción moderno se basa en la musicalidad del cuerpo y del espacio, un sentido del ritmo, una habilidad que se contrapone a la música, o mejor dicho, que se vincula a la acción, al movimiento en la no-música, al silencio. Esta disciplina, según Le Breton (1990), prolonga la metáfora mecánica en los propios movimientos del cuerpo, que se actualiza en cada ensayo, y se expresa en una forma particular de incorporar los movimientos y la música. Se educa el cuerpo para que mantenga una postura correcta a lo largo de la coreografía, respetando el tiempo y el espacio donde se produce la acción y el movimiento. Disciplinar el cuerpo para que pueda expresar lo que el coreógrafo exige.

Extracto 14

82. Y: Cuando no utilizo música, hay musicalidad en los pasos.

83. Las bailarinas la desarrollan realmente, si te has formado con gente como

84. Merce Cunningham, o Trisha Brown desarrollas un sentido increíble del

85. tiempo. Una vez aprendes una frase, puedo por ejemplo describirte esta

86. sección de la habitación. Lo hacemos en silencio,

87. y muy pronto somos capaces de desarrollar cuánto dura

88. esta sección, casi al segundo, y que sea repetible.

89. Sin escuchar ninguna música.

El proceso de aprendizaje moderno y neoclásico es distinto al del ballet clásico. En la línea 82 se refiere a una musicalidad de los pasos, independientemente de que no haya música, pero resulta que esta musicalidad es producida a través de los movimientos del cuerpo. Un cuerpo que se mueve a un ritmo, un tiempo, que han incorporado la bailarina. El proceso práctico de ensayo es básico para el aprendizaje de este sentido del ritmo sin necesidad del acompañamiento musical (ext.14, 89). Una vez aprendida la frase, la bailarina sabrá, intuitivamente, cuánto dura el paso que debe hacer a continuación. Más allá de la música, una buena bailarina desarrolla una capacidad para establecer la duración de un movimiento, de un paso, de una frase, que va más allá de llevar la cuenta o el compás (84-85).

En el trabajo etnográfico, se ha observado al coreógrafo utilizar diferente música en las tareas, un tipo de instrucción coreográfica que favorece el trabajo de improvisación de la compañía. La música es una herramienta del proceso de creación. El coreógrafo integra elementos musicales de forma diversa a la tradición clásica en ballet. En los ensayos, intercala tres tipos de música reproducida desde su lector mp3, y no de un pianista dirigido por un director de orquestra, cómo es el caso en la danza clásica. Intercala distintos tipos de música desde electrónica clásica, cómo Johan Johansson o Max Richter, hasta piezas más hardcore, de compositores como Ben Frost, con sonidos duros y hasta molestos, como el de una sierra eléctrica, pasando también por melodías barrocas, de base vocal, o piezas clásicas de Mozart, ligeras y de ritmo fácil. No existe una correspondencia entre la música presente en el momento de los ensayos y la pieza final. La partitura para la representación no se introduce hasta dos semanas antes de la première, en la que McGregor consolida las frases, las 
posiciones y el tiempo de la coreografía. Las bailarinas no pueden crear a partir de la música del proceso de creación ya que ésta cambia constantemente.

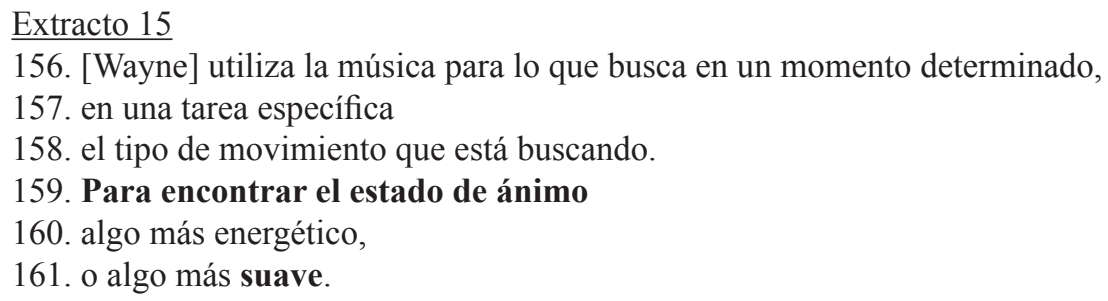

Los miembros de la compañía son conscientes de que el coreógrafo mezcla los tres tipos de música para modificar el ambiente del estudio, para conseguir un cierto estado de ánimo (159-161) que lleve a movimientos más rápidos, más lentos, más bruscos, o más suaves, dependiendo de su intención coreográfica. La música no sería, cómo reclama el habitus neo-clásico, un simple telón de fondo para la danza. Durante la mayor parte del tiempo en el ensayo suena música que modifica la dinámica del movimiento y que favorece un estado de concentración activo y un ritmo constante de creación.

\section{Extracto 16 \\ 103. W: Creo que lo que pasa en la fase de estructuración es \\ 104. que tengo los parámetros de la pieza. Tengo una \\ 105. organización, porque la organización es en parte \\ 106. musical. Es caligráfica.}

En este fragmento de entrevista al coreógrafo, encontramos un elemento que se enfrenta tanto al conductismo lírico de la tradición clásica cómo al independentismo musical de la danza moderna. Al hablar de la fase de estructuración, de organización, en la que se cierra la pieza, la música toma un papel central para el mismo coreógrafo, como elemento organizativo (106) que le permitirá finalizar la pieza como producto para ser visto en un teatro. Se trata de un estímulo sensorial y cultural que se inserta en las dinámicas de aprendizaje, constituyendo un elemento del marco cultural del ensayo (Goffman, 1983). Es cultural también el conocimiento del propio cuerpo, por parte de los bailarines, que permite expresar este independentismo musical, según Le Breton (1990). La música no importa mucho, o importa demasiado y por eso el coreógrafo prefiere no quedarse con una sola pieza o género. Mientras que el habitus moderno privilegia la musicalidad sin música, nos encontramos con que la forma de estructurar la pieza reserva un lugar importante a la música. La música es sinónimo aquí de caligrafía, un atributo lingüístico que lleva a pensar la coreografía desde una perspectiva lineal, formalista, y de búsqueda de la perfección por parte del coreógrafo.

\subsection{La memoria de las bailarinas: la música cómo herramienta}

En los dos extractos siguientes, la bailarina (ex.17) y la coreógrafa (ex.18), introducen en sus narrativas dos elementos claves para entender una de las múltiples relaciones entre música y cuerpo en la danza contemporánea: el espacio y el tiempo. 
Extracto 17

127. D: Música y espacio, cómo si te

128. despertaras. Una vez te sabes los pasos,

129. a veces te olvidas. Cada día es distinto. $\mathrm{Si}$,

130. también buena memoria. Con una gama amplia de

131. posibilidades, y grandes cambios de estado de ánimo.

Extracto 18

132. Y: Es memoria corporal y un sentido de

133. memoria temporal también. Y puedes repetir. Puedes

134. repetir lo que estás haciendo casi al segundo. Es una

135. habilidad particular que los bailarines aprenden y que

136. creo es bastante única. Es una especie de

137. consciencia que desarrollas, del cuerpo y del tiempo. Y

138. lo adquieres no solo mediante la improvisación.

139. Por ejemplo, hacemos otra tarea, yo les doy

140. alguna cosa para empezar a trabajar, y entonces digo

141. ok, vamos a improvisar hasta que diga basta. Y a veces

142. paro, al cabo de 10 segundos. Digo, que empiecen y

143. entonces digo, ok, esto es interesante, repetidlo. Y

144. tienen que acordarse de lo que justo han hecho y

145. intentar repetirlo.

En el primer extracto, la música acompaña al espacio, despertando movimiento con una serie de pasos que caracterizan el baile, es decir, la narración. En el segundo caso aparece el cuerpo y el tiempo, elementos básicos para tomar conciencia de la danza y para improvisar en los ensayos. El tiempo se caracteriza por estar ritmado, programado y pautado por la música que las bailarinas escuchan mientras se mueven, mientras recuerdan cada paso. En la compañía neoclásica, el cuerpo de las bailarinas tiene que encontrar su ritmo en una música en constante cambio, mientras que en el ballet se ensaya un pieza de danza que busca la perfección del pasado, pero que cambia 'inexorablemente' por la singularidad de cada representación, por su performance. Tiempo y espacio se diferencian del ballet, ya que en los ensayos de danza contemporánea neoclásica, el coreógrafo controla la música en el ensayo, mientras que en danza clásica la partitura pre-existe a la entrada en el estudio.

La coreógrafa insiste en esta importancia del cuerpo y de la música, sugiriendo que cuerpo y música son sinónimos del espacio y del tiempo. Estas dos dualidades, música/espacio y cuerpo/tiempo, se entremezclan en la narración $(132,133,137)$.

$\mathrm{Su}$ producto es movimiento, iteración que el espectador contempla en la representación.

La misma coreógrafa explica la habilidad de utilizar el mismo espacio (cuerpo) como elemento de memorización, una cola de memorización especial que se contrapone a la de la música (ex.18, 133). Utiliza el verbo 'repetir', en cambio, la bailarina para explicar el mismo proceso utiliza otra construcción discursiva, otros verbos, como 'despertarse'. Se trata del mismo proceso, una frase de danza, pero los dos sujetos lo expresan de manera distinta. Una memoria del ritmo y del tiempo para la primera, y del espacio y del movimiento para la segunda. Esta diferencia narrativa resulta de la distancia entre lo que ve la coreógrafa y lo que ven las mismas bailari- 
nas que forman parte de la coreografía. Para la bailarina la música es, en parte, una herramienta memorística, pero se trata de una de las dimensiones de esta relación música-danza, que como vemos es compleja. En cambio, la coreógrafa define este mismo proceso como totalmente ligado a la memoria corporal y temporal (ex.18, 132-133). Reconoce que esta capacidad es única, adscrita únicamente a las bailarinas (ex.18, 135). Una memoria que se adquiere de diferentes maneras (improvisación, repetición, regularidad, recuerdo, etc.). La dualidad música/espacio pasa aquí a ser la complementariedad entre la consciencia del tiempo y del cuerpo (time awareness/ body awareness), es decir, entre la habilidad de ser consciente del paso del tiempo y del espacio que rodea a las bailarinas en movimiento. En estos dos extractos del mismo proceso viene explicado por parte de la coreógrafa cómo ella piensa e imagina el movimiento de las bailarinas, y también cómo este movimiento se materializa. Se trata de un cuerpo que se repite para la coreógrafa, y un cuerpo que se despierta para las bailarinas.

\author{
Extracto 19 \\ 149. W: Los bailarines son muy territoriales con lo que han \\ 150. hecho, sabes, mis chicas están muy acostumbradas a \\ 151. hacer algo, y distribuirlo, pero algunas bailarinas son muy: \\ 152. "Esto es mío, esto es mío", sabes, no quieren que se \\ 153. cambie. \\ 154. E: ¿Como respetas esta territorialidad? \\ 155. W: Creo que tienes que respectar su autoría. \\ 157. Creo que si los bailarines no poseen la frase, \\ 158. lo puedes adivinar cuando lo miras, \\ 159. hay una relación de intencionalidad que desaparece. \\ 160. Pasan a ser menos interesantes.
}

La postura de la coreógrafa A. coincide con la del coreógrafo W., que identifica una consecuencia espacial de esta repetición corporal: la territorialidad (149). En efecto, los bailarines se sienten autores de una frase que han compuesto en un momento y espacio determinado, como pudimos entender en extractos anteriores. El espacio del estudio de ensayo es objeto continuo de negociación entre coreógrafo y bailarinas, se trata de un territorio en disputa. El coreógrafo, cuando habla de las bailarinas, utiliza un pronombre posesivo, 'mías' (150), y habla de cómo las bailarinas consideran las frases creadas en el estudio "suyas" (152). En esta doble relación de posesión se cruza el proceso creativo del coreógrafo y las emociones de las bailarinas, dentro de la definición de autoría artística (155). Es a partir de este conflicto entre cuerpos y roles que se construye la coreografía (159-160), por lo que el coreógrafo es consciente de la importancia creativa de esta relación entre cuerpos e intencionalidad.

\title{
Extracto 20
}

70. D: Así que hay secciones en las que no contamos,

71. sólo sabemos, reconocemos, cuando oyes este sonido,

72. es cuando necesitas estar aquí

73. en este lugar específico de la frase. 
Cabe señalar que el tiempo y el espacio en la danza, resulta mucho más complejo que un simple binomio entre música y cuerpo. Sin embargo, a nivel metodológico, este binomio es lo que nos permite hablar de tiempo y espacio en la danza, a través de las narrativas producidas por los entrevistados. El proceso de identificación entre música y cuerpo aparece también en el discurso de las bailarinas. D. explica su experiencia de escucha como cognitiva (71) desencadenada por un estímulo musical (71). De acuerdo con el significado de performatividad, podemos entender esta interacción entre cuerpo y música como lo que pasa "aquí y ahora", en aquel determinado contexto que explica la bailarina ('cada día es distinto' 129, 'necesitas estar aquí' 72). La música conecta un espacio, un "aquí", un paso determinado (72) con un momento, la secuencia temporal de movimientos que es una frase (73). Este "aquí y ahora", que se refiere al espacio y al tiempo, no puede ser reducido a la localidad concernida y limitada (Massey, 2005). Primero, porque el tiempo, y en este caso la música, siempre remite al movimiento, a la danza, que nace de un proceso de interconexión con el espacio, y nunca de oposición al espacio ${ }^{5}$. Segundo, porque el espacio (cuerpo), lejos de estar "ya allí" en movimiento, se constituye a través de interacciones (de la música, de los pasos de danza y entre los bailarines). Massey (2005) argumenta que el espacio es "la esfera donde distintas trayectorias coexisten, [...], es la esfera donde coexiste la heterogeneidad". Para la geógrafa feminista, el espacio "nunca puede estar cerrado, siempre habrá extremos sueltos, siempre relaciones con el más allá, siempre posibles elementos de cambio" (Massey, 2005: 95). El cuerpo y su danza nunca pueden estar 'estáticos' cuando hay una música u otros cuerpos cercanos ('despertarse', ex. 17, 128, 'reconocemos cuando oyes, ex. 20, 71). La música que despierta el cuerpo genera una 'gama amplia de posibilidades', 'grandes cambios de estado de ánimo' (ex. 17, 130-131), generando entonces un amplio espectro de emociones, a través de espacios y geometrías. Según la bailarina, siempre es el propio cuerpo el que reconoce esta música, ('te despiertas', 'te sabes', 'te olvidas', ex. 17, 127-129), es este cuerpo generador de espacio. Podemos imaginar el cuerpo como la simultaneidad de diferentes narrativas construidas a través de la música.

El extracto siguiente es también de la bailarina D.. Vemos cómo la música aparece de forma explícita en su discurso, e interviene de forma muy rápida, emocional e intuitiva (ex. 21,74-75), requiriendo una modificación o adaptación, el término utilizado por la bailarina, de la danza a la música (76). Se trata de un proceso que por su rapidez resulta ser inconsciente, es decir, irreflexivo (77). La entrevistada utiliza un lenguaje especialmente ambiguo, sensual y subjetivo, parece hablar con un lenguaje clásico y contemporáneo a la vez. Juega a nivel emocional con las intérpretes de la danza: la música sugiere, conduce, anima y ayuda a recordar (78-81). Se trata de un recorrido emocional en el que la bailarina narra esta música y los pasos que cumple su cuerpo al escucharla. Música y bailarina construyen una relación emocional que se encuentra en todo contexto social entre sujetos que narran una experiencia. Para Le Breton (1990), la imagen del cuerpo es la representación que la bailarina hace del cuerpo; la manera en que se le aparece a través del contexto social y cultural.

Como bien argumenta Meunier (2010), en los últimos veinte años, muchos pensadores sociales y culturales, han participado en una discusión teórica sobre el concepto de espacio, denominados "el giro espacial". Por esta razón, aconsejamos para un mayor profundización de este tema revisar Thrift (2006). 


\section{Extracto 21}

74. D: Puede crear un tipo de atmósfera, y de repente puede

75. que cambie y diga oh, mucho más rápido que esto, $\mathrm{y}$

76. entonces tienes que adaptarte un poco.

77. A veces no te das cuenta que estás escuchando la música,

78. pero cuando cambia sí que te das cuenta, te lleva mucho,

79. en tu humor, en si te sientes cansada o no.

Y en el extracto siguiente vemos cómo la música es un elemento que llama, efectivamente, a un proceso memorístico. Por lo tanto, a partir de la narrativa de D., vemos cómo la música es caracterizada cómo el agente productor de grandes cambios emocionales y una herramienta memorística crucial, mientras que es parte de la memoria temporal del coreógrafo (música como comprensión del ritmo y secuencia, ex.14, 90; ex.18, 145).

\section{Extracto 22}

122. D: Si él está creando y no te acuerdas de a dónde va la

123. cabeza, entonces oyes el cambio de música y entonces es:

124. "Oh sí, aquí va la cabeza". Así que a veces puede

125. desencadenar cuando de hecho es demasiado tarde, si lo

126. recuerdas sólo entonces, pero puede pasar.

Para D. la música es necesaria para recordar los pasos aprendidos o recién creados. La música se convierte en un importante instrumento memorístico (ex. 22, 123). En efecto, un criterio de valor central en ballet es la claridad y la rapidez de los pasos, especialmente del juego de pies y piernas de las bailarinas al sonido de la música. Las bailarinas, desde los inicios del ensayo, y guiados por el coreógrafo (la segunda persona): se acostumbran a la música, aprenden con ella, identifican los instrumentos que van a seguir según la melodía y escogen su instrumento y su posición en la pieza. Se reconoce cómo la música es importante por su factor de memorización del movimiento, del baile y del cuerpo ('Oh sí, esto es la cabeza'124). Esta memoria relaciona la música con el movimiento del cuerpo y se refleja en la repetición del movimiento. Una repetición que es iteración continua, cambiante y constante.

\subsection{El valor narrativo de la comunicación en danza}

Para la bailarina A., el público que asiste a un espectáculo de danza clásica es importante tanto para escuchar la música de Tchaikovsky como para ver la coreografía de Nijinsky o la bailarina étoile:

\section{Extracto 23}

107. A: Tienes esas producciones masivas, 100 personas en el

108. escenario, o sea que cuando la música, cuando hay un

109. gran drama todo el mundo hace el drama. Es más formal,

110. solo tienes que expresar una historia narrativa, y las más conocidas,

111. El cascanueces, El lago de los cisnes de Tchaikovski,

113. todo el mundo reconoce la música, es muy emotivo. 
Las emociones que se juegan en aquel determinado contexto, se comparten desde el principio hasta el final de la obra (113). Se comparten los mismos códigos porque el ballet es una danza formal basada en un código que establece una relación duradera entre la música y los pasos de la coreografía. Por ejemplo, un pas à deux se compone de una obertura, un adagio, dos variaciones y una coda; por lo que la limitación de los bailarines, y por extensión de la coreografía, es mayor. Dada la total identificación entre la música y la danza, los ensayos parten de la partitura de la representación y de una historia (110). Una narración representada y realizada por los sujetos presentes en el escenario, por los demás componentes de la compañía de danza (coreógrafo, músico, etc.) y también por el público, que da significado a la narración (113). Desde el punto de vista de la bailarina, existen tres personas gramaticales que construyen la narración: 1) la primera persona: los bailarines, sujetos que protagonizan la acción; 2) la segunda persona: coreógrafo y músico, que representan el vosotros que interactúa con los bailarines; 3) la tercera persona: público, un 'ellos' que está dentro de la acción, son los que dan significado al baile y a la narración. La técnica que define A. es producto de su trayectoria más clásica, pasado que se refleja claramente en su forma de explicar en el extracto siguiente, su concepción del ritmo.

\author{
Extracto 24 \\ 165. A: Que la gente ve y a la que responde en una danza. Y \\ 166. esto es distinto de la habilidad, \\ 167. la habilidad de repetir, de saber el timing, \\ 168. como un intrincado trabajo de pareja, todo se basa en \\ 169. el timing. Y esto es con lo que tienes que trabajar.
}

Las acciones de 'repetir', 'saber', se basan en el timing, todo es timing (169). Paradójicamente, el énfasis de A. en el timing mimetiza la terminología coreográfica, aún situándose en el polo del tiempo y no del espacio, cómo el caso de D.. El valor narrativo del binomio danza-música, que nace como vemos con A. de la tradición de la danza clásica y de su habitus, también aparece en la tercera bailarina que analizamos, C..
Extracto 25
114. C: Y sí, también influencia. En danza hay una historia,
115. en general la música es una historia, una
116. narrativa, esta es la belleza y la gracia del ballet.
117. Se necesita un contenido emocional que es fuerte y
118. que necesario transmitir. Claro que la música puede
119. influenciar mucho, es preciosa. La música tiene un
120. efecto enorme desde el comienzo de la creación al
121. momento de la representación.

Aparece en este extracto el término narrativa relacionado con música, que permite entender la conexión entre una narración de una historia, que puede ser el ballet, y la música, que representa también una narración. No existiría esta historia sin la música, sería imposible pensar la danza sin ella. No obstante, en la misma entrevista con C., aparece una tercera narrativa plenamente contemporánea en la que vemos otra forma de entender la música. 


\section{Extracto 26}

156. Trato de expresar o sugerir algo a la audiencia.

157. Dependiendo de cómo me siento, más agresiva,

159. hace una enorme diferencia.

160. En general en la representación trato de encontrar un viaje,

161. un viaje emocional a través de la pieza,

162. La música tiene un fuerte impacto, en el estado de ánimo.

163. Encuentro un estado emocional,

164. donde hay distintas capas, muy técnicas.

165. En la concentración,

166. busco siempre cosas nuevas en las que trabajar, o se vuelve aburrida.

167. No cambio las cosas, siento cosas distintas.

168. La música me ayuda a encontrar un cierto estado.

En su narrativa aparece un vocabulario en primera persona, en la que ella establece un diálogo directo con la audiencia, con la ayuda de la música, pero sin la mediación del coreógrafo (156). Utiliza la primera persona del verbo sentir $(157,167)$, y explicita el impacto emocional de la música en su performance con términos bien precisos de sus estados emocionales $(162,163,168)$. Esta precisión se acompaña de una conciencia narrativa al explicar la necesidad de construir una intencionalidad durante la representación (160-161). Aquí la música es importante no tanto como memoria sino como motivación de búsqueda hacia la creatividad y la innovación $(166,167)$. Es importante destacar dos elementos más. La dimensión emocional de la música se superpone a la dimensión técnica y numérica de los pasos de danza (164-165), por lo que nos encontramos con una narrativa que une en lugar de contraponer la antigua dicotomía weberiana entre emoción y racionalidad. Además, la bailarina remarca espontáneamente, sin ser interpelada por la investigadora, que en la representación ella respeta la creación coreográfica, por lo que no modifica los pasos ni los movimientos, sino que transforma la intención, la energía con la que realiza estos pasos (167). Esta referencia nos remite directamente al extracto 19, en el que el coreógrafo de la misma compañía explicita la importancia de la intencionalidad de las bailarinas para dar sentido a la composición final.

\section{Extracto 27}

170. W: Algunos se concentran más con una tarea visual,

171. otros con una narrativa, por ejemplo ayer, cuando

172. revisamos algo que hicimos por la mañana. A. me dijo

173. 'puedes poner la música otra vez' y yo dije

174. 'necesitas la música', y ella dijo 'necesito el texto'.

175. Esto es de alguna manera el scaffolding, una forma de

176. anclarse en lo que ha estado haciendo.

177. Pero me informó de que ella todavía está en un punto

178. en que si le doy un texto así, se colgará de él y luego

179. lo necesitará. Así que tendría que trabajar con ella en

180. alguna tarea que le llevará a practicar este anclaje

181. para después no necesitarlo. 
El coreógrafo pone de manifiesto que conoce las diversas trayectorias formativas de las bailarinas y expresa su clara preferencia por aquellos que no se sirven de elementos narrativos, musicales o verbales, que considera una molestia en el proceso de memorización y de creación. Si la música es una herramienta memorística, puede interferir en la memoria espacial que parece ser la habilidad más reconocida en el currículum de la danza moderna (space awareness/body awareness). La idea es que una bailarina que necesite palabras, sonidos o música, no ha desarrollado completamente su musicalidad espacial, esta habilidad central del habitus de la danza moderna y contemporánea. El uso de las palabras 'scaffolding' y 'anclaje' $(175,180)$ remite a una práctica obsoleta, que no permite hacer un cambio, una evolución de las características de las bailarinas. Naturalmente tiene una connotación negativa en este contexto. La narratividad es algo que, como vimos en el los extractos anteriores con las narrativas de las bailarinas, aparece continuamente, porque sin esta narratividad no existiría la danza. El coreógrafo de una compañía de danza contemporánea va justamente en oposición de esta narratividad, por lo que surgen conflictos y negociaciones complejas que se encuentran a la raíz de la creatividad en el estudio, como vemos con la territorialidad de extracto 19. Es importante que las bailarinas estén preparadas, pero al referirse muchas veces a ellas con verbos en pasado, el coreógrafo parece remitirnos siempre a una condición negativa y de contrariedad (176-177).

\footnotetext{
Extracto 28

182. W: Creo que es como una forma de hablar. Si estuviera trabajando con 183. alguien como A., sé que cómo tiene un background muy clásico, 184. recibe el movimiento en relación con la música, no lo puede evitar, y 185. esto deja una huella importante en su fisicidad. Así que si le doy lo 186. que llamaría una frase neutral, algo que no es muy melódico, algo que 187. es bastante uniforme, dinámicamente, sería muy susceptible al tipo de 188. música que le pondría al bailarlo. Sería una frase que rítmicamente no 189. estaría cargada. Por ejemplo en Entity veo que una de las cosas que 190. físicamente es romantizar el movimiento. No lo puede evitar, 191. añade una capa extra de significado que no ayuda 192. a las características que quiero dar a las frases.
}

Otra vez aparece el pasado como forma de desprestigiar alguna bailarina (183), por una frase neoclásica y neutra que el coreógrafo considera sin tonalidad ni dinamismo, llana. En otras palabras, "con poca música". Él mismo explica cómo una formación clásica lleva a seguir la música de forma lírica, como elemento central de la expresividad de la bailarina. Esta descripción de los habitus de las bailarinas, que también se insertan en su corporalidad ('su fisicidad', 185), indica que en una formación moderna la bailarina no seguiría tanto esta narrativa musical, sino simplemente se concentraría en su frase.

El coreógrafo es consciente de que algunos bailarines siguen un habitus clásico que condiciona su relación con la música (tiempo) pero también con el espacio (cuerpo): explica cómo sus cuerpos hacen movimientos "romantizados" (190) que siguen un habitus clásico, y que no se adecuan al habitus de su estilo neoclásico. Incluso, afirma que esta forma de moverse perjudica la calidad del producto, su coreografía, ya que esta forma de hacer crea un producto también romántico, clásico. Es interesante ver como aquí el coreógrafo se posiciona como autor y establece una 
correspondencia entre el proceso de creación y el tipo de producto resultante, lo que puede indicarnos una de las características de este habitus en danza. Se trata de una habilidad relacionada con el espacio y el tiempo, una forma de mover el cuerpo y utilizar la música como herramienta de memorización y de expresión, pero también, una forma de moverse que marca el producto coreográfico de un estilo o género en la danza.

\section{Conclusiones}

Este artículo constituye una aplicación práctica de una etnografía como metodología para la investigación social en la danza. La etnografía requiere la adquisición de un conocimiento detallado de la comunidad de prácticas en la cual uno se inserta como investigador. La inclusión de entrevistas nos permitió acceder a la dimensión subjetiva del proceso colectivo donde el diálogo entre danza, música y audiencia, puede resultar problemático, pero necesario.

Tanto las bailarinas como los coreógrafos utilizan, siguiendo su habitus correspondiente, clásico o neoclásico, la música como proceso de creación. Las diferencias giran en torno a la memorización de los pasos. El aprendizaje neoclásico es distinto al del ballet clásico: si en el ballet la sincronización se obtiene gracias a la música, en la danza neoclásica el sentido de coordinación nace de la interacción con los otros miembros del grupo. Una buena bailarina desarrolla una capacidad para establecer la duración de un movimiento, de un paso, de una frase, que va más allá de llevar la cuenta o el compás. El habitus neoclásico privilegia la musicalidad sin música, aunque el trabajo específico de la compañía observada reserva un lugar importante a la música en el momento de estructurar la pieza. Como sostienen Becker, Faulkner y Kirshenblatt-Gimblett (2006) en su etnografía sobre las improvisaciones artísticas en múltiples disciplinas, la música cómo sujeto contribuye a terminar la obra de arte, momento clave de todo proceso creativo.

El habitus en danza configura el trabajo de interpretación de las bailarinas, que desarrollan su sentido de musicalidad interna de forma interactiva e independiente de la música de ensayo. Este sentido de musicalidad interna es inherente a la danza neoclásica y constituye el motor para la creación. La lucha de Merce Cunningham y Wayne McGregor, por ejemplo, al rehusar bailar para la música, sino con la música, tiene como objetivo expandir la creatividad de las bailarinas mediante la musicalidad interna, no necesariamente siguiendo los estímulos de la música ambiental. Las bailarinas entrevistadas son conscientes de este proceso, difícil y laborioso, pero lo consideran positivo. El desarrollo de un sentido del tiempo les permite llegar a imaginar movimientos nuevos y originales en el momento de improvisación, y al resolver las tareas que propone el coreógrafo. En palabras de C.: "Lo desconocido puede llevarte a caminos más interesantes".

El habitus individualizado en cada uno de los extractos analizados configura una relación particular entre el espacio y el tiempo, el cuerpo y la música. Podemos afirmar que cuerpo (espacio) y música (tiempo) construyen la narrativa del "espectácu1o" (Débord, 1967). No obstante, el tiempo y el espacio neoclásico se diferencian del ballet, ya que en los ensayos de la danza contemporánea neoclásica, el coreógrafo controla la música en el ensayo, mientras que en danza clásica la partitura pre-existe a la entrada en el estudio. La postura de la coreógrafa A. coincide con la del coreó- 
grafo W., que identifica una consecuencia espacial de esta repetición corporal: la territorialidad.

Gracias al análisis del trabajo etnográfico, hemos observado una fuerza conjunta de música, emoción y cuerpo. Podemos afirmar entonces que además del principio de heteronimia entre música y danza, existe en la danza contemporánea, y más concretamente en la compañía observada, conflictos de tipo comunicativo, creativo y emocional entre bailarinas y coreógrafo. Se trata de un conflicto macro, que surge de un enfrentamiento de tradiciones, y que tiene efectos micro en el desarrollo de los ensayos y de nuevas coreografías en el día a día. Para la bailarina, la música es, en parte, una herramienta memorística, pero se trata una de las dimensiones de esta relación música-danza, que como vemos es compleja. En cambio, el discurso coreográfico define este mismo proceso como totalmente ligado a la memoria corporal y temporal, adscrito únicamente a los bailarines. La dualidad música/espacio pasa aquí a ser la complementariedad entre la consciencia del tiempo y del cuerpo (time awareness/body awareness), es decir, entre la habilidad de ser consciente del paso del tiempo y del espacio.

De acuerdo con el significado de performatividad de Austin (1962), podemos entender esta interacción entre cuerpo y música como lo que pasa "aquí y ahora" (Massey, 2005). Según la bailarina, es siempre el propio cuerpo que reconoce esta música ('te despiertas'), es este cuerpo el productor de espacio, el mismo espacio. El cuerpo pasa a ser las narrativas construidas simultáneamente a través de la música. Existe en definitiva entre las bailarinas una conciencia del impacto emocional de la música que implica definir el ensayo de danza como un tipo de experiencia musical fuerte (Gabrielsson y Bradbury, 2011).

Los tres perfiles narrativos de D., A. y C. nos obligan a tener en cuenta la música cómo el agente productor de grandes cambios emocionales, además de ser una herramienta memorística. La música adquiere en el discurso de los bailarines un valor narrativo, es una historia, un tejido con un valor emocional y estético, y representa la conjunción y la conexión entre estas tres personas que representa que "todo el mundo sabe que todo el mundo sabe que todo el mundo sabe" (D'Andrade, 1995). En el perfil más contemporáneo, la música es importante no tanto como memoria sino como motivación, como búsqueda hacia la creatividad y la innovación.

Finalmente, vemos cómo la música impacta emocionalmente a las bailarinas y coreógrafos, independientemente de su habitus. No obstante, el habitus sí configura la forma en la que coreógrafos y bailarinas expresan este impacto, que dependiendo de los casos, se ignora o se disimula para ser fieles al habitus neoclásico purista que identifica a la música como enemiga de la danza. Un nuevo sujeto aparece entonces en las relaciones coreógrafo/compositor/bailarinas: la música que acompaña la danza. Ella aconseja, crea movimiento e interactúa con todos los elementos del estudio. Se trata de un sujeto legítimo al interno de la compañía y no simplemente una herramienta. Un sujeto capaz de interactuar con los demás miembros de la compañía, por lo que muchos coreógrafos la temen, tienen miedo a que quite los méritos de la pieza de danza. La relación de las bailarinas con la música no tiene que ver con el aspecto creativo inicial, que es un espacio reservado al coreógrafo y al compositor como autores del proceso coreográfico. Pero sí con los procesos posteriores, momentos de trabajo en el estudio en los que la música se convierte en un sujeto que influye directamente en las emociones de la bailarina. Se crean relaciones emocionales entre sujetos que cumplen una acción conjuntamente, en este caso una danza. La experien- 
cia músico-emocional se lee en las narrativas de las tres bailarinas, cuyos perfiles surgen de sus trayectorias de aprendizaje.

Hemos visto cómo la música aparece como sujeto legítimo y como protagonista emocional en los ensayos y en el espectáculo de la compañía neoclásica observada. El discurso de los profesionales parece poner de manifiesto la importancia de la musicalidad, del tiempo (timing) y del ritmo para memorizar y aprender nuevos pasos y movimientos. La musicalidad, que parece ser la habilidad escondida de la danza, puede entenderse como el producto del habitus de la danza, pero también como una estrategia de resistencia intersubjetiva. El contenido musical sirve para crear un clima emocional: empieza la pieza, empieza la música, y las emociones en la sala se comparten. En el momento de la representación, se exige fidelidad y respeto a las restricciones impuestas a la variación individual de los cuerpos que bailan. Las funciones memorísticas, expresivas y emocionales de la música se transforman en narrativas entre los componentes de una compañía de danza contemporánea.

\section{Referencias bibliográficas}

Austin, John (1962). How to do things with words. Oxford: Clarendon Press.

Barab, Sasha; Hay, Kenneth; Yamagata-Lynch, Lisa (2001). "Constructing Networks of Action - Relevant Episodes: An In Situ Research Mehodology". The Journal of the Learning Sciences, 10: 63-112.

Becker, Howard (1982). Art Worlds. Berkeley: University of California Press.

Becker, Howard; Faulkner, Robert; Kirshenblatt-Gimblett, Barbara (2006). Art from Start to Finish: Jazz, Painting, Writing, and Other Improvisations. Chicago: University of Chicago Press.

Bourdieu, Pierre (1967). "Systems of Education and Systems of Thought". International Social Science Journal, 19(3): 367-388.

- (1991 [1980]) El sentido práctico. Madrid: Taurus.

D'Andrade, Roy (1995). The Development of Cognitive Anthropology. Cambridge: Cambridge UP.

Debord, Guy (1967). La Société du spectacle. Paris: Buchet Chastel.

Dreyfus, Hubert; Dreyfus, Stuart (1986). Mind over Machine. Oxford: Basil Blackwell.

Dreyfus, Hubert (1996). "The Current Relevance of Merleau-Ponty's Phenomenology of Embodiment" in Honi Haber \& Gail Weiss (Eds.). Perspectives on Embodiment. New York: Routledge.

Gabrielsson, Alf; Bradbury, Rod (2011). Strong experiences with music. Cambridge: Oxford UP.

Gallagher, Shaun (2005). How the body shapes the mind. Oxford: Clarendon Press.

Gallagher, Shaun; Ramsoy, Thomas (2006). "Shaun Gallagher interviewed by Thomas Ramsøy: How the body shapes the mind". Science and Consciousness Review, 45(1).

Garfinkel, Harvey (1967). Studies in Ethnomethodology. Los Angeles: Polity Press.

- (2006). Seeing Sociologically. Boulder: Paradigm Publishers.

Giere, Ronald; Moffat, Beatrice (2003). "Where the Cognitive and the Social Merge". Social Studies of Science, 33(2): 1-10.

Goffman, Erving (1969). Behavior in Public Places: Notes on the Social Organization of Gatherings. New York: Free Press.

- (1983). "Presidential address: The interaction order". American Sociological Review, 48 (1), 1-17. 
Haré, Rom (1989). "Language and science of psychology". Journal for the Theory of Social Behaviour and Personality, 4:165-188.

Kirsh, David; Muntanyola, Dafne; Lew, Amy; Jao, Joanne; Sugihara, Matt (2009). "Choreographic methods for creating novel, high quality dance". Design and Semantics of Form and Movement 2009 Conference Proceedings, 188-195.

Knorr-Cetina, Karin (1999). Epistemic Cultures. Cambridge: Harvard University Press.

Le Breton, David (1990). Antropología del cuerpo y modernidad. Buenos Aires: Nueva Visión.

Lozares, Carlos (2007). Interacción, redes sociales y ciencias cognitivas. Granada: Comares.

Massey, Doreen (2005). For Space. London: Sage.

Menin, Damiano; Schiavio, Andrea (2012). "Rethinking Musical Affordances", AVANT, 3.

Merleau-Ponty, Maurice (1962). Phenomenology of perception. New York: The Humanities Press.

Meunier, Fanny (2010). "Learner Corpora and English Language Teaching: Checkup Time". Anglistik International Journal of English Studies, 21(1): 209-220.

Muntanyola. D. (2010). "Danza y cognición: el proceso de creación coreográfica", en Noya, J., Del Val F. y Pérez M. (Eds.) Musyca: Musica. Sociedad y creatividad artística. Biblioteca Nueva: Madrid.

Muntanyola, Dafne; Belli, Simone (2014). "Emociones y música en movimiento. Discursos cruzados en una compañia de danza". Trans, 18: 1-27.

Murphy, Kevin (2004). "Imagination As Joint Activity: The Case Of Architectural Interaction". Mind, Culture and Activity, 11(4): 267-278.

Noe, Alva (2005). Action in Perception. Cambridge, MA: MIT Press.

Noice, Tony; Noice, Helga (1997). The Nature Of Expertise On Professional Acting: A Cognitive View. Mahwah: Lawrence Erlbaum Associates.

Pelinski, Ramon (2005). "Corporeidad y experiencia musical”. TRANS, 9.

Rogers, Yvonne (2006). "Distributed Cognition and Communication". In The Encyclopedia of Language and Linguistic. Edited by Keith Brown Elsevier: Oxford. 181-202.

Thrift, Nigel (2006). "Re-inventing invention: new tendencies in capitalist commodification". Economy and Society, 35(02): 279-306.

Todes, Samuel (2001). Body and World. Cambridge: MIT Press.

Yeats, William Butler (1928). Among School Children. London: Macmillan Publishing Company.

Wodak, Ruth; Meyer, Michael (2003). Métodos de análisis crítico del discurso. Barcelona: Gedisa. 